DOE/ER/13191--11

DE91 007830

FEB 21109

\title{
Kinetic Studies Following State-selective Laser Excitation
}

\author{
Progress Report
}

May 1, 1990-April 29, 1991

\author{
J. W. Keto \\ Physics Department \\ The University of Texas at Austin \\ Austin, Tx. 78712
}

\section{January 1991}

Prepared for

The U.S. Department of Energy

under Grant No. DE-FG05-84-ER13191

\section{DISCLAIMER}

This report was prepared as an account of work sponsored by an agency of the United States Government. Neither the United States Government nor any agency thereof, nor any of their employees, makes any warranty, express or implied, or assumes any legal liability or responsibility for the accuracy, completeness, or usefulness of any information, apparatus, product, or process disclosed, or represents that its use would not infringe privately owned rights. Reference herein to any specific commercial product, process, or service by trade name, trademark, manufacturer, or otherwise does not necessarily constitute or imply its endorsement, recommendation, or favoring by the United States Government or any agency thereof. The views and opinions of authors expressed herein do not necessarily state or reflect those of the United States Government or any agency thereof. 


\section{Introduction}

During the past year, we have made measurements of state-to-state energy transfer cross sections and radiative lifetimes for $\mathrm{Xe}^{*}\left(6 \mathrm{p}, 6 \mathrm{p}^{\prime}, 7 \mathrm{p}\right)$ and $\mathrm{Kr}^{*}(5 \mathrm{p})$ states in xenon and krypton buffer gases. These results are relevant to kinetic models of both excimer lasers and the infrared xenon laser; and they are a significant improvement in the precision of the known radiative lifetimes.

\section{Measured quench rates}

$\mathrm{Xe}^{*}$ and $\mathrm{Kr}^{*}$ is excited in a two-photon transition(1) using a frequency doubled, dye laser with a $300 \mathrm{psec}$ pulsewidth. The time dependence of the fluorescent light intensity is determined by the distribution of arrival times for the first photon following excitation. By measuring the exponential decays as a function of pressure, we obtain a Sturm-Volmer plot, $v=v_{\mathrm{rad}}+k[n]$, whose slope determines the reaction rate $k$. We find the decay rates for excited Xe* in krypton buffers to be described by

$$
v_{q}=v_{0}+k^{(2)} x e[X e]+k^{(2)} K_{r}[K r]
$$

where $v_{0}$ is the radiative rate and $\mathrm{k}^{(2)_{i}}$ represent bimolecular reaction rates. The measured quench rates for $\mathrm{Xe}^{*}\left(6 \mathrm{p}, 6 \mathrm{p}^{\prime}, 7 \mathrm{p}\right)$ and $\mathrm{Kr} *(5 \mathrm{p})$ are shown in Table I. All states except $\mathrm{Xe} * 6 \mathrm{p}[1 / 2] 0$ and $\mathrm{Kr} * 5 \mathrm{p}[5 / 2] 2$ exhibit simple bimolecular quenching characteristics. $\mathrm{Xe}^{*} 6 \mathrm{p}[1 / 2] 0$ has been determined to be collisionally mixed with the $\mathrm{Xe} * 5 \mathrm{~d}[1 / 2] 1$ state

Table I. Radiative Lifetimes and quench rates for $\mathrm{Xe}^{*}$ and $\mathrm{Kr}^{*}$

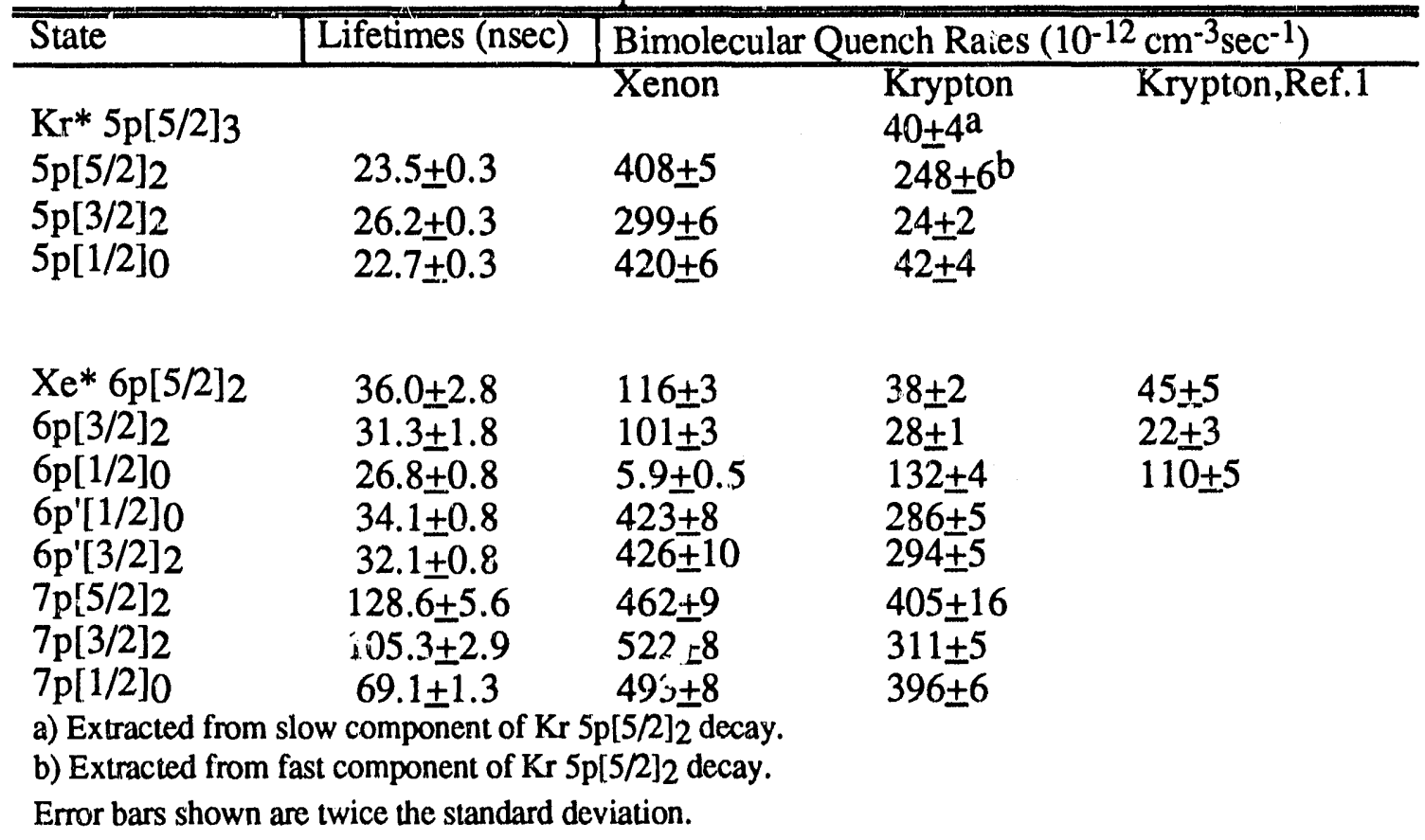


approximately $132 \mathrm{~cm}-1$ below it in energy. We determined that the time dependent fluoresence of $\mathrm{Kr}^{*} 5 \mathrm{p}[5 / 2]_{2}$ is described by a minimum of three exponentials. This state is most probably mixed with both $\mathrm{Kr}^{*} 5 \mathrm{p}[5 / 2]_{3}$ and a nearby state in the $\mathrm{Kr} * 4 \mathrm{~d}$ manifold.

\section{Measured state-to-state reaction rates}

The state-to-state reaction rates can be found from measurements of the relative integrated fluorescence intensities of the collisionally populated and laser excited states combined with the measured deactivation rates of Table I. The integrated intensity of the

v state's fluorescence is measured for all states simultaneously using an EG\&G intensified OMA mounted to a JY 620 spectrograph. In the vuv a separate monochromator is used with a uv detector (EMR \#?). All detector systems are absolutely calibrated using NIST traceable standard lamps. The relative integrated populations $\mathrm{N}_{\mathrm{i}}$ and $\mathrm{N}_{\mathrm{j}}$ are related by

$$
N_{j}=\frac{v_{i j}}{V_{i}} N_{i}
$$

where $\mathrm{N}_{\mathrm{i}}$ and $\mathrm{Nj}_{\mathrm{j}}$ are the populations of the initially excited state $\mathrm{l}>$ and the collisionally populated product state $\mid j>$, respectively. Here $v_{i j}$ is the product formation rate from $\mid i>$ to $|j\rangle$ and $v_{i}$ is the total quench rate of $\mid i>$, measure by procedure of section $\Pi$. The integrated populations $\mathrm{Ni}_{\mathrm{i}}$ and $\mathrm{N}_{\mathrm{j}}$ can be determined from the measured integrated intensities

$$
I_{i k}=\eta_{i k} A_{i k} \frac{N_{i}}{v_{i}} \text { and } I_{j k}=\eta_{j k} A_{j k} \frac{N_{j}}{v_{j}}
$$

where $\eta_{\mathrm{ik}}$ is the quantum efficiency of the optical system and $A_{i k}$ is the radiative transition probability from $|\mathrm{i}\rangle$ to $|\mathrm{k}\rangle$. An example spectra showing the excited state and various product state fluorescences is shown in Fig. 1. The state-to-state optical transition rate can be related to the measured total transition rate,

$$
A_{i}=\tau_{i}^{-1}=\sum_{k=1}^{m} A_{i k}=\sum_{k=1}^{m} b_{i k} A_{i}
$$

where $b_{i k}$ is the optical branching fraction from $\mid i>$ to $|k\rangle$. Finally, the product formation rate can be written as

$$
v_{i j}=\frac{I_{j k} \eta_{i k} b_{i k} A_{i}}{I_{i k} \eta_{j k} b_{j k} A_{j}} v_{j}
$$

hence, by measuring the relative integrated fluorescence intensities, branching fractions, optical transition rates, and total loss rates, we can obtain the state-to-state reaction rate $v_{\mathrm{ij}}$. 


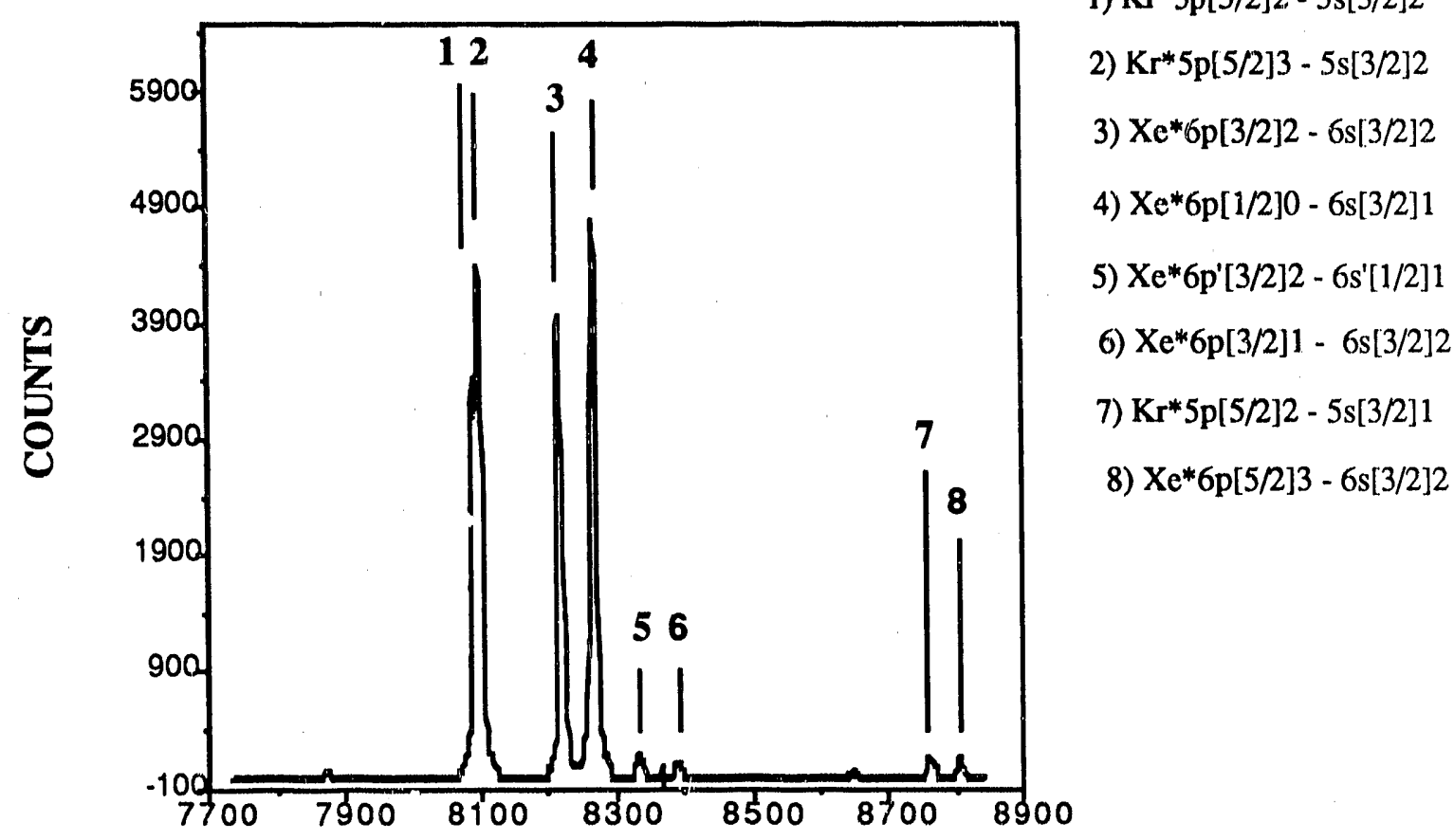

WAVELENGTH (A)

Fig. 1. Fluorescence spectra of 1 Torr krypton in 10 Torr xenon, while exciting $\mathrm{Kr}^{*} 5 \mathrm{p}[5 / 2]_{2}$.

This process is equivalent to extracting the state-to-state rates $v_{\mathrm{ij}}$ from measurements of the time dependence of the product channel. The measured time dependence of the product channel is expected to be described as the excited and product decay rates, $v_{i}$ and $v_{j}$, and a ratio of amplitudes related to the ratio of integrated intensities. Integrating the measured time dependence numerically would yield a result similar to Eq. 6 above. Since we gate the photodetector only over the necessary time window to integrate the cascade, the procedures are equivalent. Both procedures are susceptible to population of the product state though secondary channels involving a third state. As we showed earlier, this third channel can often only be detected if the signal-to-noise of the time dependence of the cascade is very good. ${ }^{2}$ If the third state decays radiatively, the existance of the secondary population,

$$
|\mathrm{i}\rangle+\mathrm{Kr} \rightarrow|3\rangle+\mathrm{Kr} \rightarrow|\mathrm{j}\rangle+\mathrm{Kr} \text {, }
$$

can also be detected by measuring the state-to-state rate $v_{\mathrm{ij}}$ in Eq. 6 as a function of pressure. If secondary channels become important (observed when the collision rates become comparable to the radiative rates), the rates $v_{\mathrm{ij}}$ are not observe to linearly increase with pressure. The effect of secondary production is minimized at the lowest pressures. 
For experiments reported here, the rates were measured at 0.1 and 0.5 Torr of the species to be excited and for collision gases pressures from 0.5 to 10Torr. An example plot of a state-to-state transition rate is shown in Fig. 2. Data for excitation of states of $\mathrm{Kr}^{*} 5 \mathrm{p}$ and $\mathrm{Xe}^{*} 6 \mathrm{p}$ ' multiplets indicate production by third channels. The product channels observed in fluorescence are indicated for these states by a "?" in the table. These states will require studies of the time dependence of the product channels. The remaining state-to-state rates are shown in Table II. As observed in Fig. 2, the state to state rate of $6 \mathrm{p}[1 / 2]_{2}$ from the excited state $6 \mathrm{p}[1 / 2]_{0}$ (marked by an asterix in the table) increases with xenon pressure indicating two possible secondary channels

$$
\begin{aligned}
& \mathrm{Xe}^{*} 6 \mathrm{p}[1 / 2]_{0}+\mathrm{Kr} \rightarrow \mathrm{Xe}^{*} 5 \mathrm{~d}[1 / 2]_{1}+\mathrm{Kr} \\
& \mathrm{Xe}^{*} 5 \mathrm{~d}[1 / 2]_{1}+(\mathrm{Kr} \text { or } \mathrm{Xe}) \rightarrow \mathrm{Xe}^{*} 6 \mathrm{p}[3 / 2]_{2}+(\mathrm{Kr} \text { or } \mathrm{Xe})
\end{aligned}
$$

and as suggested by Setser 1

$$
\begin{aligned}
& \mathrm{Xe}^{*} 6 \mathrm{p}[1 / 2]_{0}+\mathrm{Kr} \rightarrow \mathrm{Kr} * 5 \mathrm{~s}[3 / 2]_{2}+\mathrm{Xe} \\
& \mathrm{Kr}^{*} 5 \mathrm{~s}[3 / 2]_{2}+\mathrm{Xe} \rightarrow \mathrm{Xe}^{*} 6 \mathrm{p}[3 / 2]_{2}+\mathrm{Kr} .
\end{aligned}
$$

Setser prefers the latter mechanism ${ }^{1}$, in part because of its obvious xenon dependence. Since it is now known that $\mathrm{Xe}^{*} 5 \mathrm{~d}[1 / 2]_{1}$ has a rapid quench rate in xenon ${ }^{3}$, reactions 8 and 9 are also expected generate a larger rate for increasing xenon pressures. As futher support of the process described by Eq. 8 and 9 , we observe a bright fluorescence of $\mathrm{Xe}^{*} 5 \mathrm{~d}[1 / 2]_{1}$ at $125 \mathrm{~nm}$. This is indicated by a large state-to-state rate for $\mathrm{Xe}^{*} 5 \mathrm{~d}[1 / 2]_{1}$ in Table II. We have not yet determined that fraction that each of the above processes contibutes to the production of $\mathrm{Xe}{ }^{*} 6 \mathrm{p}[3 / 2]_{2}$, and this problem will as well require additional work. The

\begin{tabular}{|c|c|c|c|c|c|c|c|c|c|c|}
\hline State & $\mathrm{Xe}^{*}$ & $\mathrm{Xe}^{*}$ & IXe & $1 \mathrm{Xe}^{*}$ & $\mathrm{Xe}$ & $\mathrm{Xe} \mathrm{e}^{*}$ & $\mathrm{Xe}^{*}$ & $\mathrm{Xe}^{*}$ & $\mathrm{Xe}^{*} \mid \mathrm{Xe}^{*}$ & $\mathrm{Kr} *$ \\
\hline $\begin{array}{l}\bar{K} r^{*} \\
5 p[5 / 2] 2\end{array}$ & $\begin{array}{l}6 s[3 / 2] 1 \\
?\end{array}$ & $6 \mathrm{p}[5 / 2] 2$ & $6 p[5 / 2] 3$ & $6 p[3 / 2]_{1}$ & $\begin{array}{c}6 \mathrm{p}[3 / 2] 2 \\
?\end{array}$ & $\begin{array}{c}6 \mathrm{p}[1 / 2] 0 \\
?\end{array}$ & $\begin{array}{c}5 \mathrm{~d}[1 / 2] 1 \\
?\end{array}$ & $6 p^{\prime}[3 / 2] 2$ & $26 \mathrm{p}^{\prime}[1 / 2] 16 \mathrm{p}^{\prime}[1 / 2] 0$ & $\begin{array}{l}5 s[3 / 2] 1 \\
350 \pm 175\end{array}$ \\
\hline $5 \mathrm{p}[3 / 2] 2$ & $?$ & & & & $? 19 \pm 6$ & $? 30 \pm 8$ & & & & $280 \pm 140$ \\
\hline $\begin{array}{l}5 \mathrm{p}[1 / 2] 0 \\
\mathrm{Xe}^{*}\end{array}$ & $?$ & & & & $? 25 \pm 4$ & $? 26 \pm 4$ & & & & $280 \pm 140$ \\
\hline $6 \mathrm{p}[5 / 2] 2$ & $?$ & & $?$ & $?$ & $?$ & $?$ & & & & \\
\hline $6 \mathrm{p}[3 / 2] 2$ & 17 & & ? & $9.1 \pm 1.4$ & & $1.5 \pm 0.8$ & & & & \\
\hline $\begin{array}{l}6 \mathrm{p}[1 / 2] 0 \\
6 \mathrm{p}^{\prime}[3 / 2] 2\end{array}$ & $\begin{array}{l}57 \pm 20 \\
193+22\end{array}$ & & & & $\begin{array}{l}\begin{array}{l}27 \pm 5 \\
46 \pm 9\end{array}\end{array}$ & $6 \pm 4$ & $\begin{array}{l}48 \pm 20 \\
7 \pm 4\end{array}$ & & & $41 \pm 20$ \\
\hline $\begin{array}{l}6 \mathrm{p}^{\prime}[1 / 2] 0 \\
7 \mathrm{p}[5 / 2] 2\end{array}$ & $\begin{array}{l}0 \pm 45 \\
64 \pm 16\end{array}$ & & & $38 \pm 16$ & $\begin{array}{l}64 \pm 16 \\
24 \pm 5\end{array}$ & $\begin{array}{l}73 \pm 16 \\
16 \pm 3\end{array}$ & $\begin{array}{l}3.5 \pm 1.7 \\
12 \pm 6\end{array}$ & $52 \pm 10$ & $7 \pm 4$ & $\begin{array}{l}70 \pm 35 \\
280 \pm 140\end{array}$ \\
\hline $7 \mathrm{p}[3 / 2] 2$ & $147 \pm 80$ & & & & & & $4 \pm 2$ & & & $160 \pm 80$ \\
\hline $\begin{array}{r}7 \mathrm{p}[1 / 2]_{0} \\
* \mathrm{see}\end{array}$ & e text & & & & $?$ & & $10 \pm 5$ & & & $280 \pm 140$ \\
\hline
\end{tabular}

Table II. Bimolecular state-to-state rates in $\left(10^{-12} \mathrm{~cm}^{3} / \mathrm{sec}\right)$ for $\mathrm{Xe}^{*}$ in $\mathrm{Krpton}$ and $\mathrm{Kr}^{*}$ in xenon. The first column lists the states excited by the laser; each additional column lists the reaction rate for a particular product channel. 
stateto-state rate shown in Table II is the rate determined from extrapolating to zero xenon pressure, and should be free of the secondary production mechanism described by Eq. 10 and 11. Finally, for states of $\mathrm{Kr} * 5 \mathrm{p}, \mathrm{Xe}^{*} 6 \mathrm{p}^{\prime}$, and $\mathrm{Xe} \mathrm{e}^{*} 7 \mathrm{p}$, product channels $\mathrm{Kr} * 5 \mathrm{~s}[1 / 2]_{0}$ and $\mathrm{Kr} * 5 \mathrm{~s}[1 / 2]_{1}$ are energetically accessible. The later radiates at $117 \mathrm{~nm}$, and was not observable in the current experiments but is possible in an existing chamber having a $\mathrm{LiF}$ window.

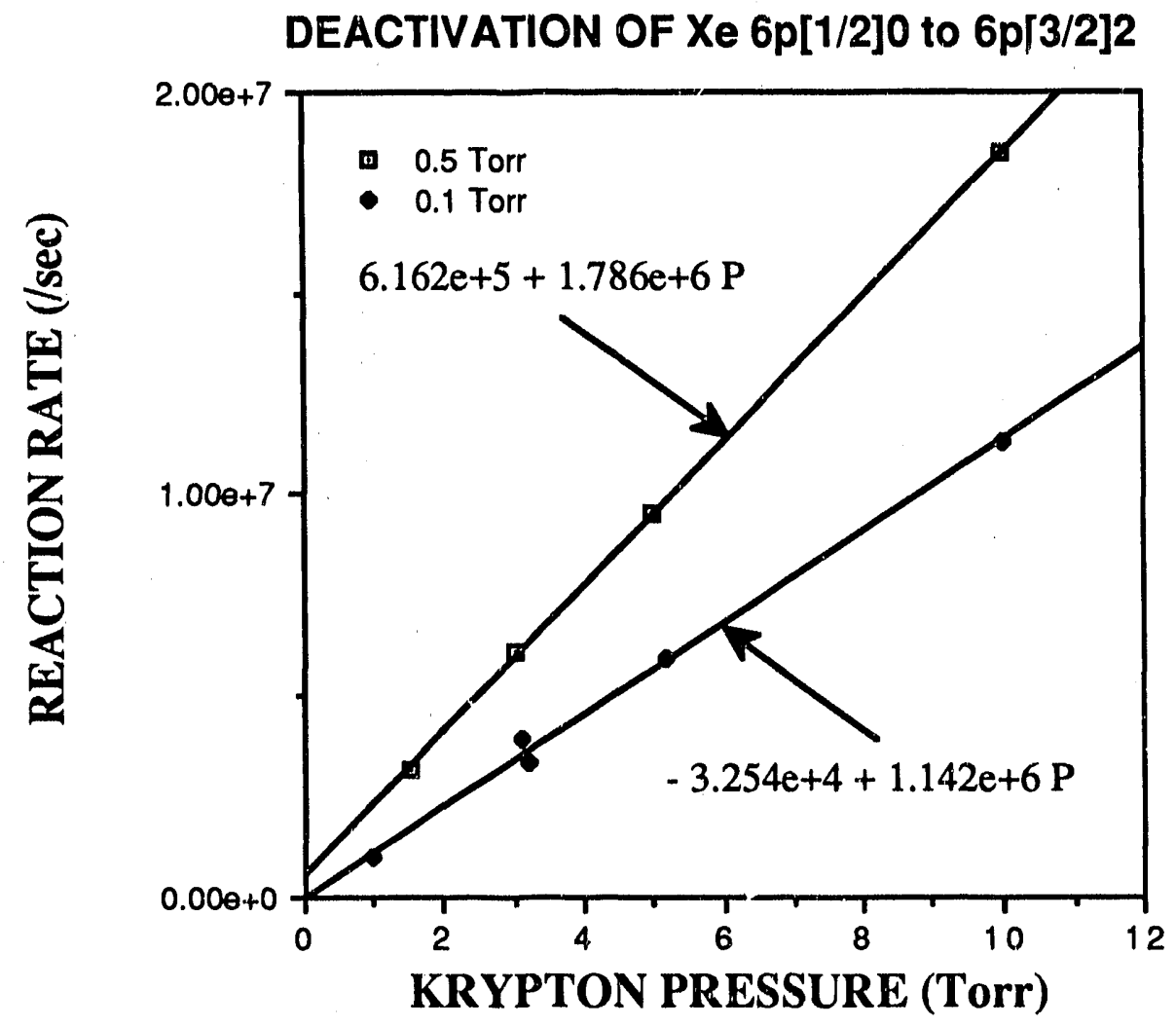

Fig. 2. State-to-state reaction rate. Here the reaction rates are function of xenon pressure, indicating that a third state is contributing to the product in a secondary reaction.

\section{Future work}

This study will be completed by the end of this contract period and will be the thesis of Andy Whitehead. For the next contract year, we plan two experiments: (1) a study of energy transfer from $\mathrm{Xe}^{*}$ to $\mathrm{Cl}_{2}$ in krypton buffers and (2) a study of the radiative collisions

$$
\mathrm{Xe}+\mathrm{Cl}_{2}+\mathrm{hv} \rightarrow \mathrm{XeCl}^{*}+\mathrm{Cl}
$$

and

$$
\begin{aligned}
\mathrm{Xe}+\mathrm{HCl}+\mathrm{hv} & \rightarrow \mathrm{XeCl}^{*}+\mathrm{H} \\
& \rightarrow \mathrm{XeH}^{*}+\mathrm{Cl}
\end{aligned}
$$


In the last process (Eq. 13 and 14), we hope to observe changes in the branching between product channels with photon energy.

\section{References}

1. J. Xu and D. W. Setser, "Deactivation rate constants and product branching in collisions of the $\mathrm{Xe}(6 p)$ states with $\mathrm{Kr}$ and $\mathrm{Ar}$ ", J. Chem. Phys.92, 4191(1990).

2. N. Boewering, M. R. Bruce, and J. W. Keto, J. Chem. Phys. 84,709(1986) and J. Chem. Phys. 84, 715(1986).

3.M. R. Bruce, W. B. Layne, A. Whitehead, and J. W. Keto, "Radiative Lifetime and Collisional Deactivation of Two-Photon Excited Xenon in Argon and Xenon", J. Chem Phys. 92, 2917(1990).

\section{Publications}

i. M. R. Bruce, W. B. Layne, Enno Meyer, and J. W. Keto,"Reactive Quenching of Two-Photon Excited Xenon Atoms by Cl2", J. Chem Phys. 92, 420(1990).

ii. M. R. Bruce, W. B. Layne, and J. W. Keto,"A Multichannel Harpoon Model for Reactive Quenching of Xe by $\mathrm{Cl}_{2}$ ", J. Chem Phys. 92, 428(1990).

iii. M. R. Bruce, W. B. Layne, A. Whitehead, and J. W. Keto, "Radiative Lifetime and Collisional Deactivation of Two-Photon Excited Xenon in Argon and Xenon", J. Chem Phys. 92, 2917(1990).

iv. M. R. Bruce, "A study of reactive quenching of xenon by chlorides using twophoton laser excitation",Ph.D. Thesis, 1990.

\section{ABSTRACTS}

i. M.R. Bruce, Hong Cai, J. Kohel, W.B. Layne, David Wheeler, C.A. Whitehead, and J. W. Keto, "Energy Disposal studies of Two-Photon Excited Xenon and Krypton", Bull. Am. Phys. Soc. 35, p. 1195(1990).

ii. M.R. Bruce, Hong Cai, J. Kohel, W.B. Layne, David Wheeler, C.A. Whitehead, and J.W. Keto, State-to-State Quenching Reactions of Two-Photon Excited Xenon and Krypton. Bull. Am. Phys. Soc. 36, p. 74(1991).

iii. Lei Chen, M. Kykta, and J. W. Keto, "T'wo-photon Excitation of Xe Clusters in a Supersonic Beam", Bull. Am. Phys. Soc. 36, p. 95(1991).

iv. Lei Chen, M. Kykta, and J. W. Keto, "Two-photon Excitation of Xe Dimers in a Supersonic Beam", Bull. Am. Phys. Soc. 36, p. 95(1991).

v. Joe P. Holder, P. Bhatia, and J. W. Keto, "Raman-Induced Kerr Effect Spectroscopy.of Discharge Excited Molecules and Molecular Ions", Bull. Am. Phys. Soc. 36, p. 86(1991).

vi. P. S. Bhatia, Joe P. Holder, and J. W. Keto, "Computer Controlled Fabry-Perot Wavemeter", Bull. Am. Phys. Soc. 36, p. 95(1991).

vii. W.B. Layne, M.R. Bruce, and J.W. Keto, Two Photon Laser Assisted Reactions in $\mathrm{Xe}, \mathrm{Cl}_{2}$ ", Bull. Am. Phys. Soc. 36, p. 95(1991). 

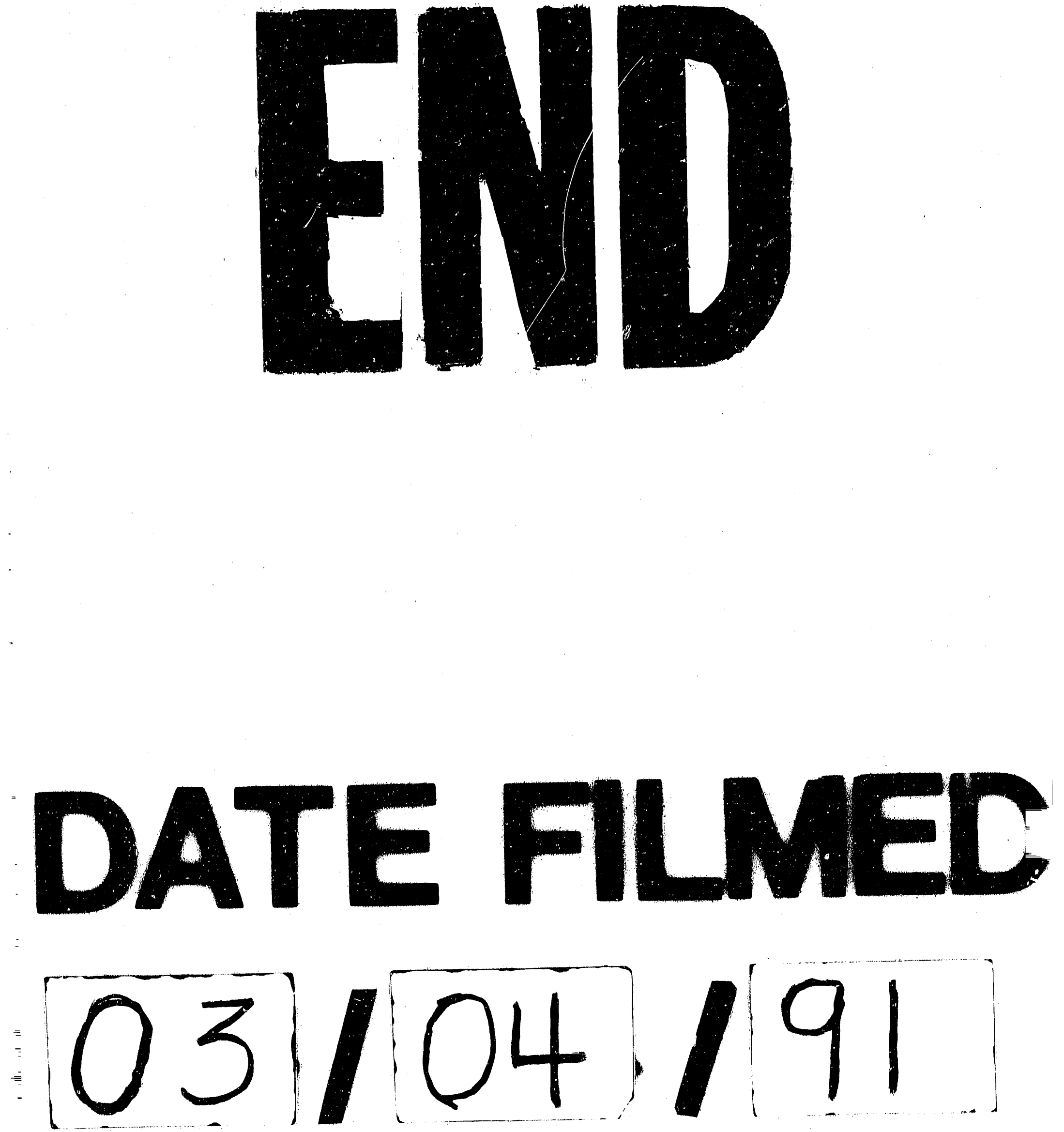
